\title{
Musculoskeletal Health Professional Use of Internet Resources for Personal and Patient Education: Results from an Online National Survey
}

\author{
Michael Nicolaou ${ }^{1,2}$, Ray Armstrong ${ }^{3}$, Andrew B. Hassell ${ }^{4}$, David Walker ${ }^{5}$ and Fraser Birrell ${ }^{*}, 1,5$ \\ ${ }^{I}$ Rheumatology, Northumbria Healthcare NHS Foundation, Ashington, Northumberland, UK \\ ${ }^{2}$ Newcastle University, Newcastle upon Tyne, UK \\ ${ }^{3}$ Department of Rheumatology, Southampton General Hospital, Southampton, UK \\ ${ }^{4}$ Medical School, Keele University, Keele, UK \\ ${ }^{5}$ Musculoskeletal Research Group, Institute of Cellular Medicine, Newcastle University, Newcastle Upon Tyne, UK
}

\begin{abstract}
Objectives: To study the current practice of computer use in musculoskeletal health professionals for their education and that of their patients.

Methods: A survey questionnaire, designed by a working group including representatives from Arthritis Research UK and the British Society for Rheumatology, was made available on surveymonkey.com and the link distributed by email.

Results: 190 health professionals responded. Rheumatology professionals made up two thirds of the participants. The modal age group of responders was under 40 years (37\%). 97\% had spent some educational time on a computer. Females were younger and spent more time using the computer for education purposes. The preferred learning modality was interactive online content $(71 \%)$. The most common methods of educating patients were the Consultant and Specialist nurse while the web is used by $40 \%$ of the health professionals. The most common barrier to education was 'Insufficient resources for education groups'. Rheumatologists were more likely to log Continuous Professional Development (CPD) online, complete online modules and have mandatory training online. UpToDate and Arthritis Research UK were the highest rated websites for health professional and patient education respectively.

Conclusions: This is the first national survey of E-learning in the musculoskeletal health profession, with a large proportion of Rheumatologists. Almost all use computer based learning. Use of the internet for patient education is low. Highly rated educational websites are available for both professionals and patients.
\end{abstract}

Keywords: Computers, health, internet, musculoskeletal, education, e-learning.

\section{INTRODUCTION}

With advances in technology, easier accessibility and decreased costs, the internet has become a popular tool for learning. It has been reported by the Office of National Statistics that approximately $77 \%$ of the United Kingdom (UK) population in 2011 has access to the internet (web) [1]. Prior studies have suggested that e-learning (in this report it refers only to computer based learning) is an effective learning tool [2-5]. It has been used in medical education but there is no robust evidence to support its use by health professionals for their own or their patient's education within the musculoskeletal professions and specifically in Rheumatology.

Patient education plays a vital role in the health care of patients (especially for chronic diseases) and has been widely used [6-9]. It has been shown to improve their understanding about the disease process and its management

*Address correspondence to this author at the Musculoskeletal Research Group, 4th Floor Cookson Building, Framlington Place, Newcastle University, Newcastle upon Tyne, NE2 4HH, UK;

Tel: 0044-01670529903; Fax: 0044-01670529446;

E-mail: Fraser.Birrell@newcastle.ac.uk leading to improvements in clinical outcome and selfefficacy. A recent systematic review outlined the positive effects (clinical and psychological) of patient education on Rheumatoid Arthritis patients [9]. In this review apart from the improvement in disease-related knowledge, outcomes and the psychological advantage, it was reported that the use of patient education has been associated with improvements in self-management as well as a decrease in health costs.

E-learning as a means of educating patients is relatively new with a relatively low utilisation by health professionals. It was reported by a study in the United States (US) that 40$50 \%$ of the US population in 2003 obtained health information online and almost $50 \%$ of these individuals preferred searching the web first while only $10.9 \%$ went to the physician first [10]. A different report found that only $3 \%$ of patients received a doctor's advice to seek health information on the internet while $62 \%$ agreed that they should be guided by their doctor [11]. The low use of the internet for obtaining health information was linked to the variability in quality of information found on the internet. A patient based survey explored how participants used the internet for health information [12]. The population comprised adults older than 18 years attending outpatient clinics during a two week period in a major city 
(Nottingham) in the UK. They found that $63 \%$ of the study subjects (sample of 663) had access to the internet while $42 \%$ had used the internet to obtain health information in the past. Almost all of the subjects in this study who had used the internet felt that the information they obtained was above average while four out of five subjects reported that they would like to access trustworthy information.

Musculoskeletal healthcare involves dealing with chronic disease in which education is an important aspect of care and it is therefore of great interest to study how it is affected by e-learning. Reports in the past from a health professional perspective have shown benefits for the use of computer based learning in patient education and healthcare [13, 14]. There are no previous reports studying the use of computer based learning specifically in musculoskeletal healthcare from the medical professionals' perspective. This study addressed this issue and furthermore made an assessment of currently available patient and professional educational web resources in this field.

\section{MATERIALS AND METHODOLOGY}

A survey devised by a group of healthcare professionals with input from various Rheumatology and Orthopaedic organisations (British Society for Rheumatology (BSR), Arthritis Research UK (ARUK), British Health Professionals in Rheumatology, Primary Care Rheumatology, British Orthopaedic Association and trainees, including the Rheumatologists at Training \& British Orthopaedic Trainees Association) was placed on an easily accessed website (surveymonkey.com). A link to the survey was placed in the BSR E-newsletter of 14 September 2010. Where feasible, reminders were sent electronically, either to the same mailing list, or by cascading emails through regional administrative leads. The survey ended on the $8^{\text {th }}$ of November 2010.

Participants were anonymous and the survey consisted of 16 questions relevant to health professionals' educational practice and personal characteristics (Table 1). No confidential information pertaining to patients was requested. Two of the questions required rating of a number of websites listed by the British Society of Rheumatology for education purposes (for both health professionals and patients). Questionnaire responders had the option to suggest unlisted websites along with a rating. A Likert rating system $(0=$ worst to $5=$ best $)$ was used for rating the websites. The complete questionnaire can be accessed via "http://www.surveymonkey.com/s/BSR-

Arthritis_Research_UK_National_E-Learning_Survey"

Statistical analyses were performed using Microsoft Excel, 2003. The chi-square statistic or two sample t-test were used for all comparisons. 95\% Confidence Intervals (CI) about the mean were calculated for the website ratings. An alpha value of 0.05 was chosen for significance purposes.

\section{RESULTS}

192 individuals had completed the survey. Two were excluded because they reported a profession other than healthcare. The characteristics of the responders are presented in Table 2. Individuals from at least twelve health professions relating to musculoskeletal care responded. There was almost equal representation of male and females and the majority were 50 years of age or younger. A higher proportion of females were noted in the younger age groups. 124 of the responders were within the Rheumatology profession

Table 1. Questions Asked in the e-Learning Survey

\begin{tabular}{|ll|}
\hline 1. & What best describes your position? \\
\hline 2. & Gender \\
\hline 3. & Age range \\
\hline 4. & How much time spent on education is done using a computer? \\
\hline 5. & Where do you prefer using a computer for your own education \\
& purposes? \\
\hline 6. & Reasons for not using the computer for education purposes \\
\hline 7. & Is any of your trust mandatory training online? \\
\hline 8. & Have you ever completed an online module of any description? \\
\hline 9. & Do you have a preferred format for e-learning material? \\
\hline 10. & Do you have an online CPD Diary or Portfolio? \\
\hline 11. & How do your patients currently receive education? \\
\hline 12. What barriers exist to educating patients? \\
\hline 13. Which resources are you aware of for professionals? \\
\hline 14. Which resources are you aware of for patients? \\
\hline 15. What is the single most important thing that defines a good online \\
educational resource? \\
\hline 16. Please provide us with the first part of your postcode \\
\hline
\end{tabular}

\section{Health Professional Computer Based Education}

Most (>97\%) health professionals use a computer for education purposes (Table 2). Almost $70 \%$ of the respondents stated that they used a computer for education purposes in $20 \%-80 \%$ of their study time. The time devoted to computer use was inversely proportional to the age of the study participants with the younger individuals using the computer more than their older counterparts. More males reported using the computer for education purposes for shorter periods of time ( $\leq 40 \%$ of computer education time) while more females used the computer for education purposes for longer periods $(>40 \%$ of computer education time). $69 \%$ of musculoskeletal health professionals responded that they use computers for education purposes at work and at home. The small percentage of respondents who did not use a computer stated that they preferred attending courses and reading books. They also cited time pressure and dislike of using a computer.

$87 \%$ of the study participants had completed an online module. Three quarters reported doing mandatory training online at their employing trust. Two thirds $(67 \%)$ kept a CPD Diary or Portfolio. The interactive online content format was the most frequently used $(71 \%)$ while use of the Podcast (audio) was not listed by any respondents (Other responses to format included: Blogs/Forums 8\%, Podcast-video 18\%, PowerPoint $29 \%$, RSS Feeds $3 \%$, and Webcast $10 \%$ ). 
Table 2. Participant Characteristics, Education Time Using a Computer and Place of Computer Use

\begin{tabular}{|c|c|c|c|c|}
\hline \multirow{3}{*}{ Characteristics } & \multicolumn{4}{|c|}{ Website Use for Patient Education } \\
\hline & N (\%Total) & Yes & No & \multirow{2}{*}{$\underset{\text { P-Value }}{\chi^{2}}$} \\
\hline & \multicolumn{3}{|c|}{ Frequency (\%) } & \\
\hline Profession & $\mathrm{N}=190$ & $\mathrm{~N}=76$ & $\mathrm{~N}=114$ & \\
\hline Academic Rheumatologist & $21(11)$ & $11(15)$ & $10(9)$ & 0.220 \\
\hline General Practitioner & $9(5)$ & $5(7)$ & $4(4)$ & 0.325 \\
\hline GPwSIR & $11(6)$ & $4(5)$ & $7(6)$ & 0.817 \\
\hline Rheumatology Trainee & $45(24)$ & $15(20)$ & $30(26)$ & 0.294 \\
\hline General Practitioner Trainee & 1(1) & $0(0)$ & 1(1) & 0.407 \\
\hline Physical Therapist & 2(1) & 2(3) & $0(0)$ & 0.084 \\
\hline Occupational Therapist & 2(1) & 2(3) & $0(0)$ & 0.084 \\
\hline Podiatrist & $7(4)$ & 1(1) & $6(5)$ & 0.152 \\
\hline Other & $20(11)$ & $7(9)$ & $13(11)$ & 0.628 \\
\hline \multicolumn{5}{|l|}{ Gender } \\
\hline Male & $91(48)$ & $37(49)$ & $54(47)$ & 0.861 \\
\hline Female & $96(51)$ & $38(50)$ & $58(51)$ & 0.903 \\
\hline \multicolumn{5}{|l|}{ Age Group (Years) } \\
\hline $0 \%$ & $5(3)$ & 2(3) & $3(3)$ & 1.000 \\
\hline $1 \%-20 \%$ & $43(23)$ & $22(29)$ & $21(18)$ & 0.089 \\
\hline $20 \%-40 \%$ & $49(26)$ & $20(26)$ & $29(25)$ & 0.892 \\
\hline $40 \%-60 \%$ & $43(23)$ & $18(24)$ & $25(22)$ & 0.778 \\
\hline $60 \%-80 \%$ & $39(21)$ & $11(14)$ & $28(25)$ & 0.092 \\
\hline $80 \%-100 \%$ & $7(4)$ & $3(4)$ & $4(4)$ & 0.875 \\
\hline \multicolumn{5}{|c|}{ Place of Computer Use for Education Purposes } \\
\hline Home & $37(19)$ & $9(12)$ & $28(25)$ & $0.028^{*}$ \\
\hline Work & $18(9)$ & $12(16)$ & $6(5)$ & $0.012 *$ \\
\hline Both & 131(69) & $55(72)$ & $76(67)$ & 0.468 \\
\hline
\end{tabular}

Percentages may not sum up exactly to $100 \%$ due to missing values or rounding off.

* Statistically significant at $\alpha=0.05$.

GPwSIR $=$ General Practitioner with Special Interest in Rheumatology.

\section{Computer Based Patient Education}

$40 \%$ of the participants reported that their patients receive education via the web (either using their departmental website or some other website) (Table 3). The most common consultation channels reported were the specialist nurse $(83 \%)$ and the consultants $(80 \%)$. Arthritis Research UK leaflets and booklets were used more often than other printed material. The most commonly reported barrier $(60 \%)$ to patient education was insufficient resources 
Table 3. Means by which Patients Receive Education and Barriers to Education

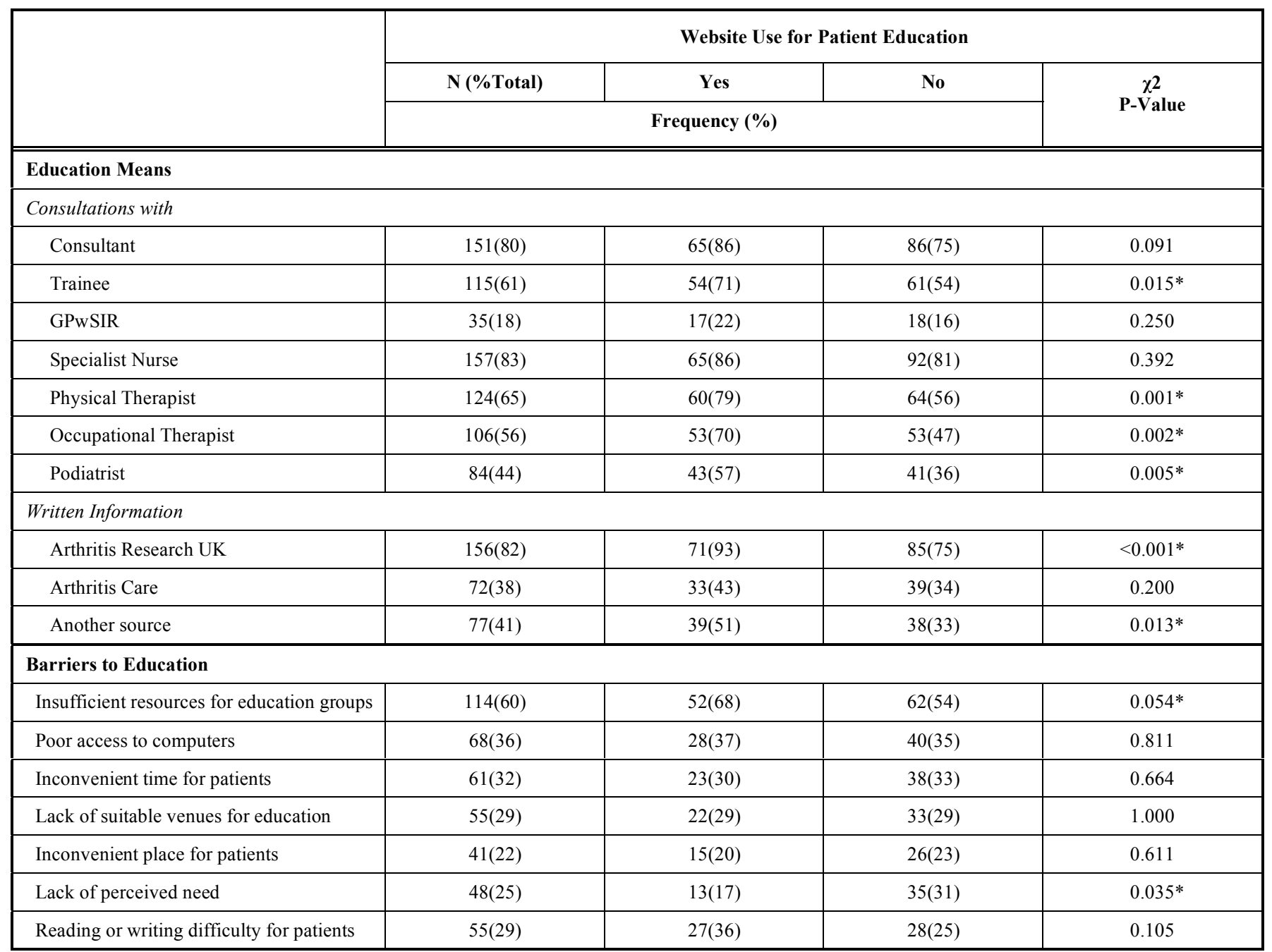

Percentage for each education modality and barriers are calculated from total $\mathrm{N}$ as each health professional may use multiple methods for their education.

All percentages are rounded off.

* Statistically significant at $\alpha=0.05$.

GPwSIR $=$ General Practitioner with Special Interest in Rheumatology .

for education groups while literacy (reading or writing difficulties of patients) was seen as a barrier in $29 \%$ of the survey participants.

161 of the 190 respondents presented their post codes. 90 were coded as being from the south of the UK (areas south of Sheffield) and 71 were from the North of the UK (areas north of Sheffield). $39 \%$ of the participants from the south reported the internet as a mode of education for the patients while $42 \%$ did the same from the north of the UK. This difference was not statistically significant $(\mathrm{p}=0.7)$.

\section{Health Professional Practices of Computer Based Learning Stratified by the Use of the Web}

The study sample was stratified by the use of the web as a modality for patient education and compared in a number of questions. The frequencies of the characteristic variables (profession, gender and age group) did not differ among the two groups (see Table 2 for p-values). The amount of time using a computer in education was not associated with using the web for patient education $(\mathrm{p}=0.479)$. Furthermore no statistically significant differences in the time spent using the computer for education among the web users and those that don't use the web for patient education was noted for any of the time subgroups (p-values shown in Table 2). No significant differences were also noted for CPD use, completing an online module and mandatory training online ( $p$-values are shown in Table 4A). The choice of e-learning format did not differ among the two groups ( $\mathrm{p}$-values $=1.00$, $0.750,1.00,0.540,0.850,0.170,0.490$ for Blogs/Forums, Interactive online content, Podcast-audio, Podcast-video, PowerPoint, RSS Feeds, and Webcast respectively).

\section{Education Among Professions (Rheumatology vs Non- Rheumatology Professionals)}

Due to the high proportion of Rheumatologists within our study participants, responses to all study questions were compared between the Rheumatologist group $(\mathrm{N}=124)$ and all other health professionals $(\mathrm{N}=66)$. A higher percentage of younger professionals was noted in the Rheumatology group (age group specific comparison of proportions by Chisquare: $<40$ years, $\mathrm{p}<0.001 ; 40-50$ years, $\mathrm{p}=0.482 ; 50-60$ years, $p<0.001 ; 60-70$ years, $p<0.001)$. The amount of computer time for education purposes was not statistically 
different between the Rheumatologist and NonRheumatologist groups $(p=0.835)$. The percentage of Rheumatologists that used the computer for education purposes at home was lower than the percentage of NonRheumatologists. The opposite was noted for computer use at work or the combination of both home and work. NonRheumatologists preferred Blogs as a method of e-learning $(p=0.107)$. There was a $9 \%$ higher completion of online modules by Rheumatologists $(p=0.066)$ (Table 4B). Availability of mandatory training in the workplace was more common for the Rheumatologists $(\mathrm{p}<0.001)$ by almost $30 \%$. Rheumatologists were also two times more likely $(p<0.001)$ to have an online CPD Diary or Portfolio. The only significant difference in the barrier question was that Rheumatologists had listed 'lack of perceived need' less than the Non-Rheumatologists. There was no statistically significant association between profession and the use of the web for patient education $(p$-value $=0.504)$ although a higher proportion of Rheumatologists used the web for patient education (42\% vs 37\%).

Table 4. Use of CPD, Mandatory Online Training and Online Modules Stratified by Web Use (A) and Profession (B)

\section{A: Web Use}

\begin{tabular}{|l|c|c|c|}
\hline \multirow{2}{*}{} & \multicolumn{2}{|c|}{$\begin{array}{c}\text { Web Use for Education } \\
\text { of Patients }\end{array}$} & $\chi^{2}$ \\
\cline { 2 - 4 } & Yes & No & P-Value \\
\hline \hline CPD & & & \\
Yes & $55(73 \%)$ & $72(64 \%)$ & 0.194 \\
No & $20(27 \%)$ & $40(36 \%)$ & \\
\hline Mandatory Online Training & & & \\
Yes & $58(77 \%)$ & $80(73 \%)$ & 0.480 \\
No & $17(23 \%)$ & $30(27 \%)$ & \\
\hline Online Module & & & \\
Yes & $69(91 \%)$ & $97(87 \%)$ & 0.469 \\
No & $7(9 \%)$ & $14(13 \%)$ & \\
\hline
\end{tabular}

\section{B: Profession}

\begin{tabular}{|l|c|c|c|}
\hline \multirow{2}{*}{} & \multicolumn{2}{|c|}{ Rheumatologist } & $\chi^{2}$ \\
\cline { 2 - 4 } & Yes & No & P-Value \\
\hline \hline CPD & & & \\
Yes & $98(80 \%)$ & $28(44 \%)$ & $<0.001^{*}$ \\
No & $24(20 \%)$ & $36(56 \%)$ & \\
\hline Mandatory Online Training & & & \\
Yes & $102(84 \%)$ & $35(56 \%)$ & $<0.001^{*}$ \\
No & $19(16 \%)$ & $28(44 \%)$ & \\
\hline Online Module & & & \\
Yes & $112(92 \%)$ & $53(83 \%)$ & 0.066 \\
No & $10(8 \%)$ & $11(17 \%)$ & \\
\hline
\end{tabular}

*Statistically significant at $\alpha=0.05$.

$\mathrm{CPD}=$ Continuous Professional Development.

\section{Web Resources for Health Professional and Patient Education}

Due to the small number of other websites that were listed by the participants only those offered by the survey were included in the results. There were 27 website resources for health professional education and 37 website resources for patient education. Multiple websites received more than a $50 \%$ response rate (range $14 \%$ - $82 \%$ ). All websites received a rating of 2 and higher out of a maximum scale of 5 (best). The range of mean rating scores for the education of health professionals was $2.24-4.19$ while that for patient education was $2.53-4.14$. Among the list of websites for the education of health professionals UpToDate received the best rating with a mean score of 4.19 (95\% CI 3.96-4.42) while for the education of patients, Arthritis Research UK was the highest ranked website with a score of 4.14 (95\% CI 3.99-4.29). The complete list of ranked websites for health professional education is shown in Table 5 while those for patient education in Table $\mathbf{6}$. There were no significant differences in the website ratings among those that use the web for patient education and those that don't (results not shown). Similarly no statistical differences were noted when stratified by gender for both patient education and health professional education websites. There were multiple factors that Health professionals listed as the most important criterion that defines a good educational resource. The most common criteria were the user-friendliness of the website, clarity and accuracy as well as ease of access. The number of websites rated by a participant was not significantly associated with web use but a larger number of websites was noted to coincide with a higher proportion of individuals using the web for patient education.

\section{DISCUSSION}

This survey has shown that almost all musculoskeletal health professionals responding to an email invitation and completing an online survey use the computer for their own education purposes (both at home and at work). There is high use $(>67 \%)$ of mandatory training online, CPD and completion of online modules. Females spent more time using computer-based education while younger responders tended to use the computer to a greater extent. This is consistent with existing literature indicating that older individuals use computers less (including those for obtaining health information) [15]. The preferred format for e-learning was interactive online content.

Although the web is used increasingly to obtain health information (greater than $50 \%$ of individuals that search the web seek health information) [16, 17], this study has shown that only $40 \%$ of musculoskeletal health professionals reported that their patients obtain health education via the web. This percentage although being the view of the musculoskeletal health professionals (which may not match the actual usage of the web by their patients) is below expectation. Patients may use the internet to obtain health information even though it is not an education method used by their health care professional (in which case their health care professional may or may not be aware) or they may not use the web to obtain health related information even though 
Table 5. Health Professionals Ratings of Websites for Health Professional Education ( $0=$ Worst, $5=$ Best)

\begin{tabular}{|c|c|}
\hline Website & Mean $(95 \% \mathrm{CI})$ \\
\hline Up-to-date (www.uptodate.com) & $4.19(3.96-4.42)$ \\
\hline Pubmed (www.ncbi.nlm.nih.gov/pubmed) & $3.77(3.56-3.98)$ \\
\hline Arthritis Research UK formerly arc (www.arthritisresearchuk.org) & $3.68(3.53-3.83)$ \\
\hline Medscape (www.medscape.com)/Emedicine (http://emedicine.medscape.com) & $3.53(3.29-3.77)$ \\
\hline BMJ Learning (http://learning.bmj.com) & $3.47(3.33-3.62)$ \\
\hline EULAR On-line course (www.eular-onlinecourse.org) & $3.41(3.12-3.70)$ \\
\hline NHS Evidence (www.evidence.nhs.uk) & $3.40(3.13-3.66)$ \\
\hline NHS Clinical Knowledge Summaries (www.cks.nhs.uk/) & $3.38(3.16-3.60)$ \\
\hline The British Society for Rheumatology (www.rheumatology.org.uk) & $3.33(3.16-3.49)$ \\
\hline Google(www.google.co.uk) & $3.20(3.01-3.40)$ \\
\hline RCGP 'online learning environment' (http://elearning.rcgp.org.uk) & $3.11(2.83-3.40)$ \\
\hline Google Scholar (http://scholar.google.co.uk) & $3.10(2.90-3.30)$ \\
\hline EULAR Compendium (http://ard.bmj.com/site/about/eularcompendium.xhtml) & $3.07(2.79-3.07)$ \\
\hline EULAR On-line course on Connective Tissue Diseases (www.eular-ctd-onlinecourse.org) & $3.06(2.73-3.40)$ \\
\hline National Institute for Health and Clinical Excellence (NICE) List (www.nice.org.uk) & $3.05(2.88-3.23)$ \\
\hline EULAR (www.eular.org) & $3.05(2.86-3.23)$ \\
\hline Doctors.net (www.doctors.net.uk) & $3.02(2.80-3.24)$ \\
\hline Web Mentor (www.emis.ca/emr-system/emis-system/web-mentor-library) & $2.94(2.55-3.33)$ \\
\hline GP Notebook (www.gpnotebook.co.uk) & $2.91(2.62-3.20)$ \\
\hline Royal College of Physicians (www.rcplondon.ac.uk) & $2.85(2.61-3.08)$ \\
\hline EULAR Training DVD (www.eular.org/edu_training_dvd.cfm) & $2.74(2.40-3.08)$ \\
\hline e-Learning for healthcare (e-LfH) (www.e-lfh.org.uk) & $2.65(2.41-2.90)$ \\
\hline Univadis (www.univadis.co.uk) & $2.64(2.37-2.91)$ \\
\hline Map of medicine (www.mapofmedicine.com) & $2.61(2.26-2.96)$ \\
\hline Wikipedia (www.wikipedia.org) & $2.50(2.28-2.73)$ \\
\hline eGuidelines (www.eguidelines.co.uk) & $2.45(2.18-2.73)$ \\
\hline British Orthopaedic Association (www.boa.ac.uk) & $2.24(1.83-2.65)$ \\
\hline
\end{tabular}

they have been advised to do so. It is though comparative to prior studies from a patient perspective who have reported percentages ranging from $20 \%-50 \%$ [13, 18, 19]. In a doctor based survey completed in the UK in 2001 with a majority of General Practitioners found that only 1\%-2\% of their patients had used the internet to obtain health information in the month prior to the study [14]. Demographic location based on the subdivision of North and South of the UK revealed no difference in computer based patient education. No further stratifications in location were attempted due to small sample size. Insufficient resources for education groups, poor computer access and reading and writing difficulties were perceived to be the most common obstacles to patient education. No gender differences were noted among those that use the web versus those that don't use the web for patient education. The degree of computer use was not associated with the use of web-related material for patient education. There were several characteristics (questionnaire responses) of the participants that may be associated (although not statistically significant in this sample) with the use of the web in their patient education practices (CPD, barriers to education such as 'Insufficient resources for education groups', 'lack of perceived need' and 'reading and writing difficulties').

This survey also showed differences in education practices among the Rheumatology professionals and other professionals within the musculoskeletal field. A larger percentage of Rheumatologists used online education, mandatory training at their trust and continuing professional education (although this may partly be accounted for by the small number of study subjects from the other professional groups and also that the Rheumatologist groups were of a younger age). Nevertheless, this finding may need to be investigated further in a larger and more representative sample.

One of the greatest concerns about using computers and the web for patient education has been the variable quality of 
Table 6. Health Professional Ratings of Websites Available for Patient Education ( $0=$ Worst, $5=$ Best)

\begin{tabular}{|c|c|}
\hline Website & Mean $(95 \% \mathrm{CI})$ \\
\hline Arthritis Research UK formerly arc (http://www.arthritisresearchuk.org/) & $4.14(3.99-4.29)$ \\
\hline National Rheumatoid Arthritis Society (NRAS) (http://www.rheumatoid.org.uk/) & $3.97(3.78-4.15)$ \\
\hline National Ankylosing Spondylitis Society (NASS) (http://www.nass.co.uk/) & $3.80(3.62-3.98)$ \\
\hline National Osteoporosis Society (http://www.nos.org.uk/NetCommunity/Page.aspx?pid=183\&srcid=-2) & $3.75(3.55-3.95)$ \\
\hline Patient UK (www.patient.co.uk) & $3.73(3.45-4.00)$ \\
\hline Arthritis Care (http://www.arthritiscare.org.uk) & $3.70(3.53-3.86)$ \\
\hline Lupus UK (http://www.lupusuk.org.uk/) & $3.50(3.31-3.69)$ \\
\hline Raynaud's and Scleroderma Association (http://www.raynauds.org.uk/potioncms/viewer.asp?a=117\&z=25)) & $3.39(3.13-3.65)$ \\
\hline Scleroderma Society (http://www.sclerodermasociety.co.uk/newsite/index.php) & $3.35(3.06-3.65)$ \\
\hline Back Care (http://www.backcare.org.uk/) & $3.33(2.99-3.67)$ \\
\hline Vasculitis (http://www.vasculitis-uk.org.uk/) & $3.27(2.93-3.61)$ \\
\hline The British Society for Rheumatology (www.rheumatology.org.uk) & $3.22(3.01-3.42)$ \\
\hline British Sjogren's Syndrome Association (http://www.bssa.uk.net/) & $3.21(3.01-3.40)$ \\
\hline Fibromyalgia Association UK (http://www.fibromyalgia-associationuk.org/) & $3.14(2.88-3.40)$ \\
\hline Behcets Syndrome Society (http://www.behcets.org.uk/) & $3.13(2.85-3.41)$ \\
\hline Choices - for Families of Children with Arthritis (http://edit.arthritiscare.org.uk/LivingwithArthritis/Youngpeople) & $3.09(2.66-3.51)$ \\
\hline Hypermobility Syndrome Association (http://www.hypermobility.org/) & $3.09(2.77-3.41)$ \\
\hline British Scoliosis Society (http://www.liv.ac.uk/HumanAnatomy/phd/bss/bss.html) & $3.04(2.74-3.34)$ \\
\hline National Institute for Health and Clinical Excellence (NICE) (www.nice.org.uk) & $3.01(2.75-3.28)$ \\
\hline Ehlers-Danlos Support Group (http://www.ehlers-danlos.org/) & $3.00(2.67-3.23)$ \\
\hline Marfan Association UK (http://www.marfan-asssociation.org.uk/) & $3.00(2.66-3.34)$ \\
\hline Paget's Association (http://www.paget.org.uk/) & $3.00(2.61-3.39)$ \\
\hline Psoriasis Association (www.psoriasis-association.org.uk/) & $2.96(2.54-3.37)$ \\
\hline National Association for the relief of Paget's disease (http://www.paget.org.uk/) & $2.92(2.58-3.25)$ \\
\hline NHS Choices (www.nhs.uk) & $2.91(2.54-3.27)$ \\
\hline UK Gout Society (http://www.ukgoutsociety.org/) & $2.91(2.55-3.27)$ \\
\hline Myositis Support Group (http://www.myositis.org.uk/) & $2.89(2.60-3.18)$ \\
\hline Psoriasis and Psoriatic Arthritis Alliance (http://www.psoriasis-association.org.uk/) & $2.88(2.57-3.18)$ \\
\hline Society for Back Pain Research (http://www.sbpr.info/) & $2.86(2.35-3.37)$ \\
\hline Contact a Family (http://www.cafamily.org.uk/) & $2.85(2.47-3.23)$ \\
\hline RADAR: The Disability Network (http://www.radar.org.uk/radarwebsite/) & $2.71(2.26-3.17)$ \\
\hline Sick Children's Trust (http://www.sickchildrenstrust.org/) & $2.71(2.15-3.26)$ \\
\hline Perthes Association (www.perthes.org.uk/) & $2.63(2.23-3.03)$ \\
\hline Psoriasis Scotland (www.psoriasisscotland.org.uk/) & $2.61(2.16-3.06)$ \\
\hline FibroAction (http://www.fibroaction.org/) & $2.59(2.26-2.92)$ \\
\hline Palindromic Rheumatism Society (www.palindromicrheumatism.org/) & $2.53(2.07-2.99)$ \\
\hline Scoliosis Society (http://www.britscoliosissoc.org.uk/) & $2.44(2.05-2.84)$ \\
\hline
\end{tabular}

$\mathrm{CI}=$ Confidence Interval.

information [20-23]. Some have suggested using a validation system in grading the websites available. This is challenging in that there is a continuously expanding number of websites and also that medical information changes so rapidly that the information would need to be validated at least every few months. It was shown by this survey that musculoskeletal health professionals have rated most website resources listed on the survey as above average with a few obtaining excellent scores (UpToDate and Arthritis Research UK). More than half of the websites attained a score above 3 (best=5).

This is the first national survey of the use of computers in the education of musculoskeletal health professionals and how they utilise learning resources for their patients. As this is the current practice of musculoskeletal health professionals the results should be compared with patients' 
responses to questions about e-learning so that provision of material will have the best chance of meeting patients' needs. Furthermore it gives an assessment of current web resources that can be utilised for patient education, recommended by health professionals. The questionnaire used in this survey was newly devised by a multidisciplinary team of musculoskeletal health professionals (with good content validity). It was not possible to calculate the exact response rate since the survey was open to everyone (excluding the 45 trainee Rheumatologists the responses obtained represent approximately a $12 \%$ response rate. The gender (male to female ratio of 2 to 1 ) and age distribution (Royal College of Physicians vs survey participants: $<40$, $16 \%$ vs $13 \%$; 40-50, 44\% vs 35\%; 50-60, $29 \%$ vs $38 \%$ and $>60,11 \%$ vs $11 \%$ ) of the study sample was representative of the study population as cited by the Royal College of Physicians census of 2009) [24]. There was evidence of over-representation of younger health professionals. This is not unexpected given that younger individuals tend to use the computer more in general and thus were more likely to participate in the survey. Given that this questionnaire was administered online there is the possibility of selection bias as health professionals that use the web more would be more likely to complete it. This would tend to overestimate the percentage of computer based education for both professional and patients. There are also potential issues for generalizability since our sample was based in the musculoskeletal field and mainly consisted of Rheumatology physicians $(65 \%)$ and should thus be interpreted primarily within that population. Furthermore the sample size may not have been large enough in order to detect differences in responses especially when stratifications were made.

Results from this survey suggest that targeting e-learning characteristics may offer ways to improve patient education with the use of e-learning. For example making CPD with a diary portfolio more readily available and necessary in health professionals may increase the number that use or adjunct their patient education with the use of web resources. The barriers also need to be resolved to allow the education process to evolve. This would involve educating patients and health professionals on the advantages of e-learning, making computers more accessible, creating sustainable venues that are convenient for patients to use and utilizing different methods to overcome reading and writing difficulties, such as involving family members, friends or using study groups. Health professionals that use the web for patient education rated a greater number of websites suggesting that there should be a greater effort in educating musculoskeletal health professionals about the available quality website resources and thus establishing the web as part of their patient education. These web ratings should be used as a guide to where to search for quality information but should always be tailored to the patient needs and abilities and should always be correlated with the health professional's recommendations. Newly developed web resources should include interactive online content as a mode of web based learning but not limited in order to appeal to a wider group.

With more reliable web resources for patient education and new evidence supporting the use of e-learning in patient education it is suggested that e-learning becomes an integral part of patient education. It is thus important that health professionals understand and support its use and find ways to include it in their patient education plans. New research should be formulated to study the implementation of the web in patient education using the most appropriate methods (i.e. experimental studies). This requires a greater understanding of the patients learning practices and abilities (including social, environmental and educational factors) and taking into account the limitations relating to their illness. This may mean that future research should be disease specific as well as patient specific.

\section{CONCLUSIONS}

Almost all musculoskeletal health professionals use electronic learning resources. In this sample a gender effect was observed with a higher proportion of females utilising computer based learning for longer periods. Interactive online learning was the preferred format for computer based learning. The use of e-learning in patient education by musculoskeletal health professionals remains low even though a larger percentage of adults are accessing information on the web. Insufficient resources for education groups was the most commonly referred barrier to educating patients while literacy remains a significant barrier. There are highly rated educational web resources available for both professionals and patients.

\section{ACKNOWLEDGEMENTS}

Thanks to Yvonne Rowe and Lara Fasanya from the BSR who implemented the online questionnaire \& Sally Thomas who distributed the link in the electronic newsletter. We would also like to thank all those that took part in devising the questionnaire and those that completed the questionnaire.

\section{CONFLICT OF INTEREST}

The authors declare no conflicts of interest.

\section{REFERENCES}

[1] Office for National Statistics. Internet access - Households and individuals, 2011. Available from http://www.ons.gov.uk/ons/rel /rdit2/internet-access---households-and-individuals/2011/stb-internetaccess-2011.html [Accessed 11th of April, 2012].

[2] Cook DA, Levinson AJ, Garside S, Dupras DM, Erwin PJ, Montori VM. Internet-based learning in the health professions: a metaanalysis. JAMA 2008; 300: 1181-96.

[3] Gill A. E-learning and professional development - never too old to learn. Br J Nurs 2007; 16: 1084-8.

[4] Goettner P. Effective E-learning for healthcare. Health Manag Technol 2000; 21: 64, 63.

[5] Powell JA, Darvell M, Gray JAM. The doctor, the patient and the World-wide web: how the internet is changing healthcare. J R Soc Med 2003; 96: 74-6.

[6] Holman H, Lorig K. Patients as partners in managing chronic disease. BMJ 2000; 320: 526-7.

[7] WHO working group. Therapeutic patient education: continuing education programmes for health care providers in the field of prevention of chronic diseases. 1998. 2012. Available from: http:// www.euro.who.int/_data/assets/pdf_file/0007/145294/E63674.pdf [Accessed 22nd of February].

[8] Riemsma RP, Tall E, Kirwan JR, Rasker JJ. Systematic review of rheumatoid arthritis patient education. Arthritis Rheum 2004; 51: 1045-59

[9] Albano MG, Giraudet-Le Quintrec JS, Crozet C, d'Ivernois JF. Characteristics and development of therapeutic patient education in rheumatoid arthritis: analysis of the 2003-2008 literature. Joint Bone Spine 2010; 77: 405-10.

[10] Hesse BW, Nelson DE, Kreps GL, et al. The impact of the internet and its implications for health care providers: findings from the first health information national trends survey. Arch Intern Med 2005; 165: 2618-24. 
[11] Diaz JA, Sciamanna CN, Evangelou E, Stamp MJ, Ferguson T. Brief report: what types of internet guidance do patients want from their physicians? J Gen Intern Med 2005; 20: 683-5.

[12] Ayantunde AA, Welch NT, Parsons SL. A survey of patient satisfaction and use of the internet for health information. Int J Clin Pract 2007; 61: 458-62.

[13] Kim HA, Bae YD, Seo YI. Arthritis information on the web and its influence on patients and physicians: a Korean study. Clin Exp Rheumatol 2004; 22: 49-54.

[14] Potts HWW, Wyatt JC. Survey of doctors' experience of patients using the internet. J Med Internet Res 2002; 4: e5.

[15] Office for National Statistics. Internet access - households and individuals, 2010. Available from http://www.ons.gov.uk/ons/ search/index.html?newquery=internet + access [Accessed 28th of March, 2011].

[16] Fox S. The engaged e-patient population. Available from http:// www.pewinternet.org [Accessed $8^{\text {th }}$ of March, 2011].

[17] Fox S. The Engaged E-patient Population. People turn to the internet for health information when the stakes are high and the connection fast. Available from http://www.pewinternet.org/ / media//Files/Reports/2008/PIP_Health_Aug08.pdf [Accessed 28th of November, 2011].
[18] Gordon MM, Capell HA, Madhok R. The use of the internet as a resource for health information among patients attending a rheumatology clinic. Rheumatology 2002; 41: 1402-5.

[19] Richter JG, Becker A, Koch T, et al. Internet use in rheumatology outpatients in 2006: gender less important. Clin Exp Rheumatol 2009; 27: 15-21.

[20] Lewiecki RM, Rudolph LA, Kiebzak GM, Chavez JR, Thorpe BM. Assessment of osteoporosis-website quality. Osteoporosis Int 2005; 17: 741-52.

[21] Ansani NT, Vogt M, Henderson BAF, et al. Quality of arthritis information on the internet. Am J Health-Syst Pharm 2005; 62: 1184-9.

[22] Jadad AR, Gagliardi A. Rating health information on the internet: navigating to knowledge or to Babel? JAMA 1998; 279: 611-4.

[23] Berland GK, Elliot MN, Morales LS, et al. Health information on the internet: accessibility, quality, and readability in English and Spanish. JAMA 2001; 285: 2612-21.

[24] 2009 census - Key findings. Royal college of physicians. Available from: http://www.rcplondon.ac.uk/resources/2009-census-key-findings [Accessed 23rd June, 2011].

(C) Nicolaou et al.; Licensee Bentham Open.

This is an open access article licensed under the terms of the Creative Commons Attribution Non-Commercial License (http://creativecommons.org/licenses/by-nc/ 3.0/) which permits unrestricted, non-commercial use, distribution and reproduction in any medium, provided the work is properly cited. 